\title{
Challenges in managing a large metallic Foreign Body in Oropharynx of a child: A case report
}

\author{
Manisha Paneru ${ }^{1}$, Ajit Nepal ${ }^{1}$, and Binam Ghimire ${ }^{1}$ \\ ${ }^{1}$ Patan Academy of Health Sciences
}

July 1,2021

\begin{abstract}
Foreign Body (FB) ingestion is common condition in pediatric population .Curious nature and tendency to put objects in mouth are the key factors for its higher prevalence among them. Most of the ingested FB pass through the entire alimentary tract uneventful, however some require surgical interventions for its removal.
\end{abstract}

\section{Introduction}

Foreign body ingestion is fairly common among the pediatric population; as they tend to be very curious and have tendency to put objects in mouth . ${ }^{1}$ These ingested foreign body in upper aerodigestive tracts accounts for significant i.e. around $30 \%$ of out- of- hour referrals to ENT surgeons. ${ }^{2}$ Children of 5 years of age and younger are responsible for $75 \%$ of all $\mathrm{FB}$ ingestions ${ }^{3}$, and $20 \%$ of children 1 to 3 years of age are reported to have ingested some kind of foreign body in their life. ${ }^{4}$

Although many ingested items are relatively innocuous and pass uneventfully through the entire gastrointestinal tract and eventually through the feces, some FBs result in its impaction and can cause grievous harm necessitating surgical intervention. ${ }^{5}$

It is crucial for the prompt diagnosis and early intervention of foreign body of aerodigestive tract, to prevent morbidity (aerodigestive tract stricture, esophageal perforation) and mortality. ${ }^{6}$

At times, direct laryngoscopy has been an option to remove objects lodged at or above the cricopharyngx during induction thus avoiding the need of hypopharyngoscopy further. Rigid or flexible endoscopy remains the choice of intervention for removal of objects lodged below this area and when laryngoscopy remains unsuccessful in removing objects lodged above the cricopharynx. ${ }^{7}$

\section{CASE REPORT}

A 13-month-old female child presented to the Emergency Department of Patan Academy of Health Sciences (PAHS) Nepal, with an alleged history of accidental ingestion of large circular metallic object 1.5 hours back while playing with the same following which child had excessive drooling and noisy breathing. On physical examination, the child's pulse was $120 / \mathrm{min}$, BP $70 / 50 \mathrm{~mm}$ of $\mathrm{Hg}$, and respiratory rate of 40/min. She showed signs of inspiratory stridor and decreased air entry while lying flat. A foreign body in aerodigestive tract was suspected; thus, X-ray soft tissue neck anterior-posterior (AP) and lateral was requested which revealed a radio-opaque, vertically oriented circular foreign body in the region of oropharynx and partly extending upto naso-hypopharyngx. (Figure 1A and B). Physical examination revealed no other significant abnormalities.

Thus, rigid endoscopy (hypopharyngoscopy) was subsequently planned under general anesthesia. In the operating room child was sedated and while intubating, huge metallic container was seen which was occupying 
whole of the oropharynx and inferior part of nasopharynx with sharp margin facing anteriorly causing partial airway obstruction. . Intubation was difficult due to large size of foreign body. Further, downward manipulation was also risky due to risk of falling down to hypopharynx and getting flipped to cause the complete airway obstruction. Tracheostomy set was kept ready. Eventually after direct laryngoscopic visualization and careful manipulation of FB was removed by Freer's elevator and Magill's forceps without any trauma to soft palate or posterior pharyngeal wall. Uvula however appeared grossly edematous. On inspecting the foreign body it was a huge $(2.5 \times 2.5 \mathrm{~cm})$ metallic hollow circular $0.7 \mathrm{~cm}$ deep container having sharp edge and mirror on opposite surface. (Figure $2 \mathrm{~A} \& \mathrm{~B}$ ) Child was immediately intubated after the procedure to secure the airway and was admitted to the pediatric intensive care unit. The following day, child was asymptomatic and was transferred to pediatric ward. She was discharged on third postoperative day and was doing absolutely fine on scheduled follow up after a week.

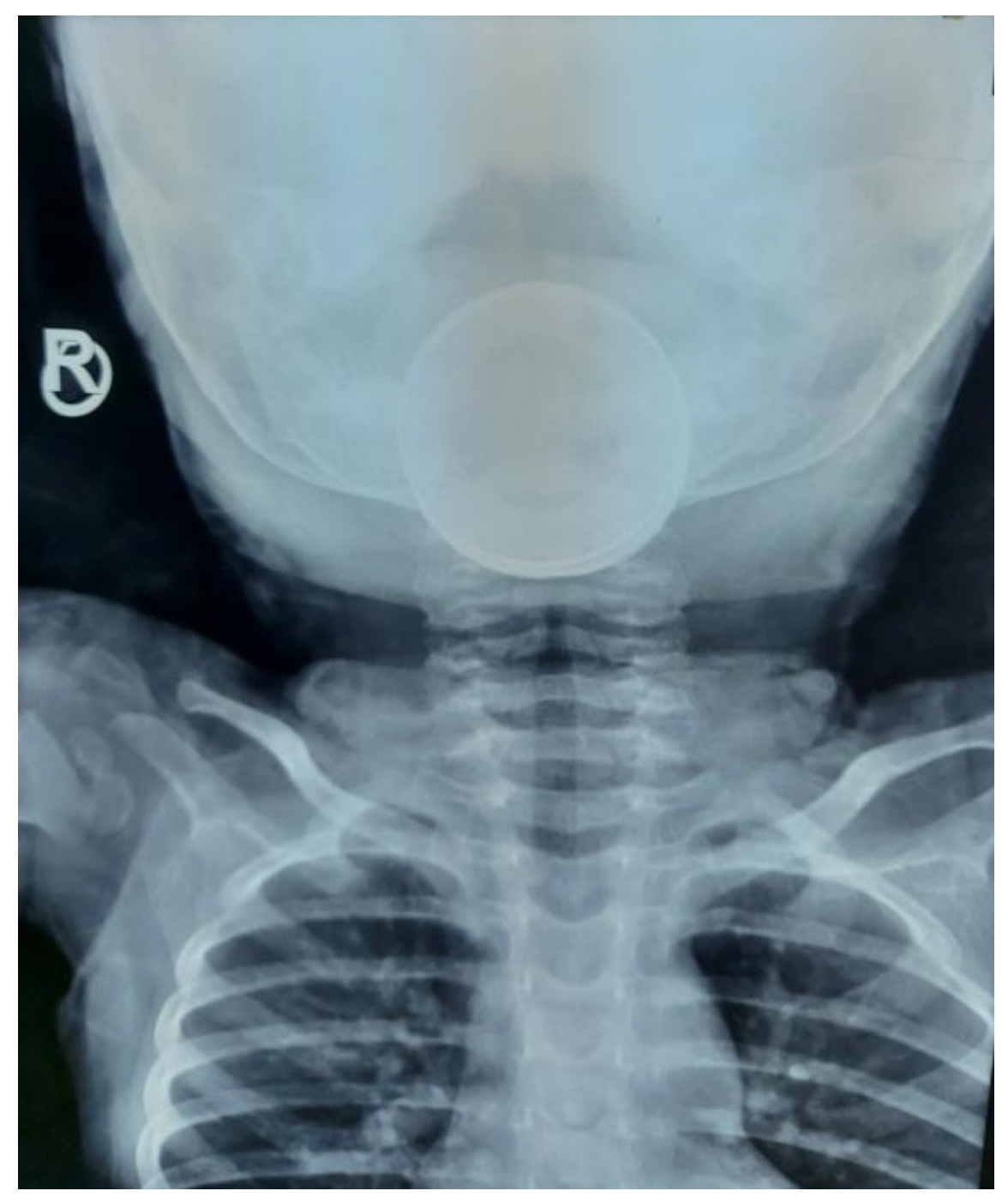




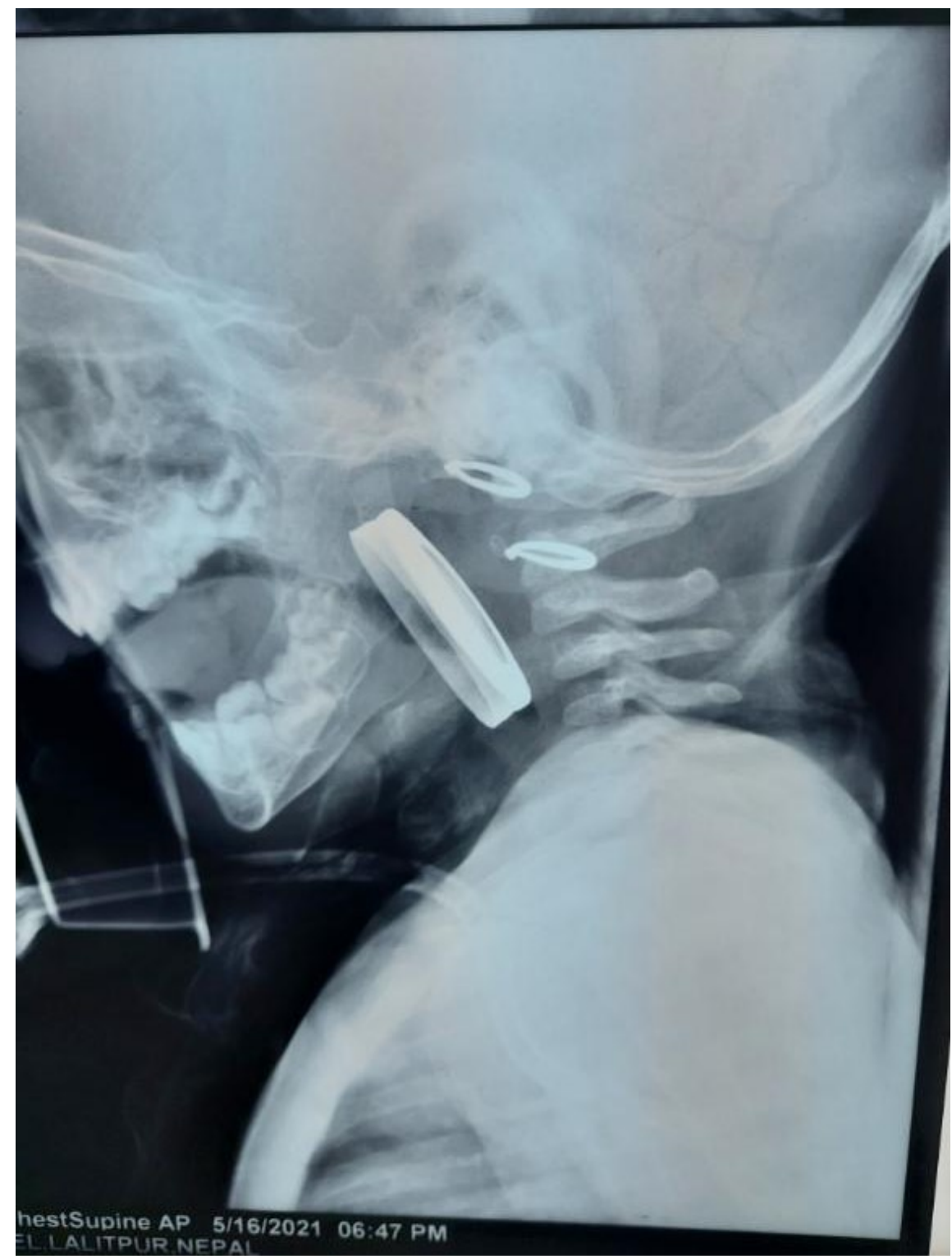

Figure $1(\mathrm{~A} \& \mathrm{~B})$ : X-ray Soft tissue neck AP and lateral view showing radio opaque foreign body 


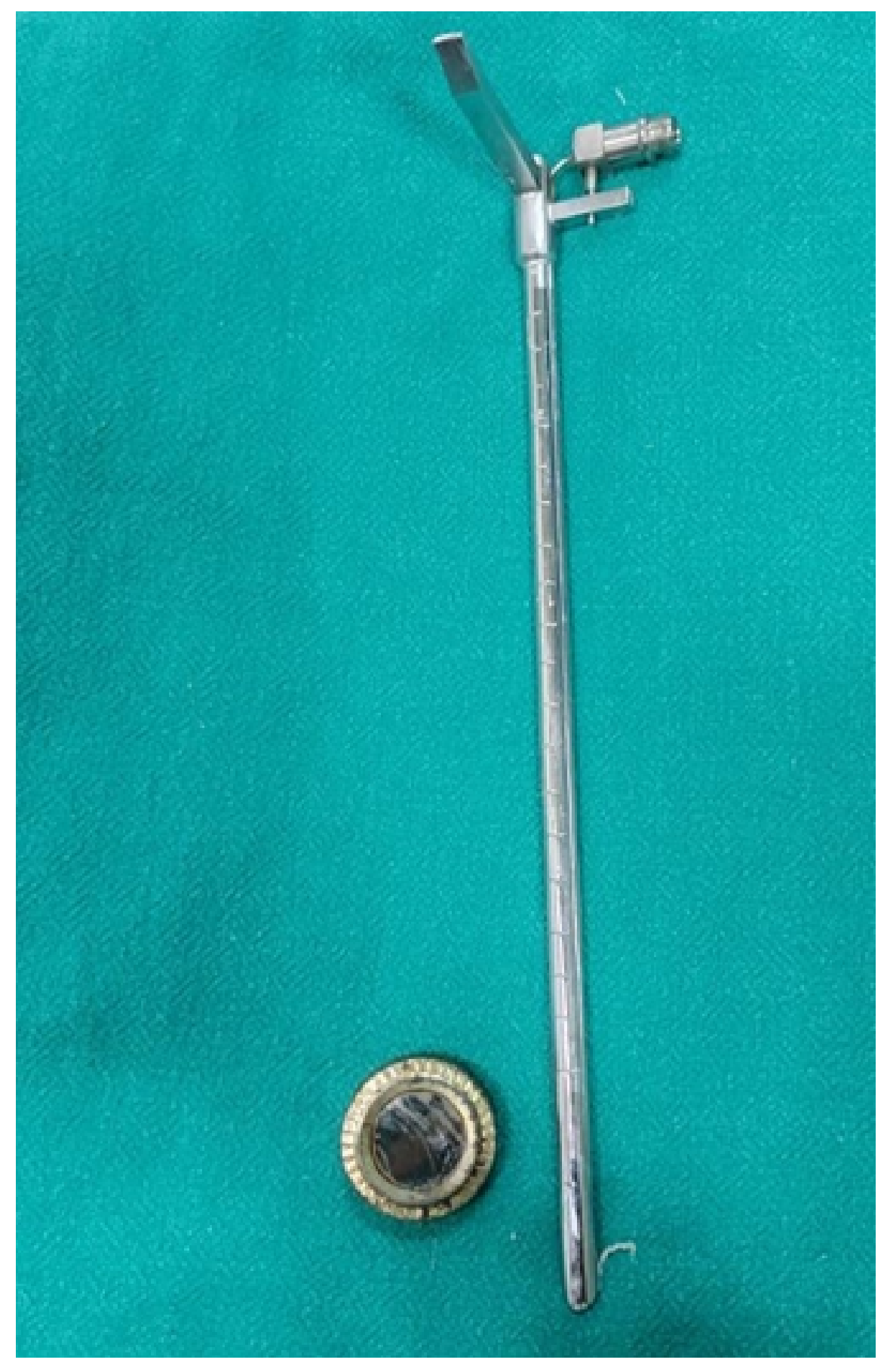




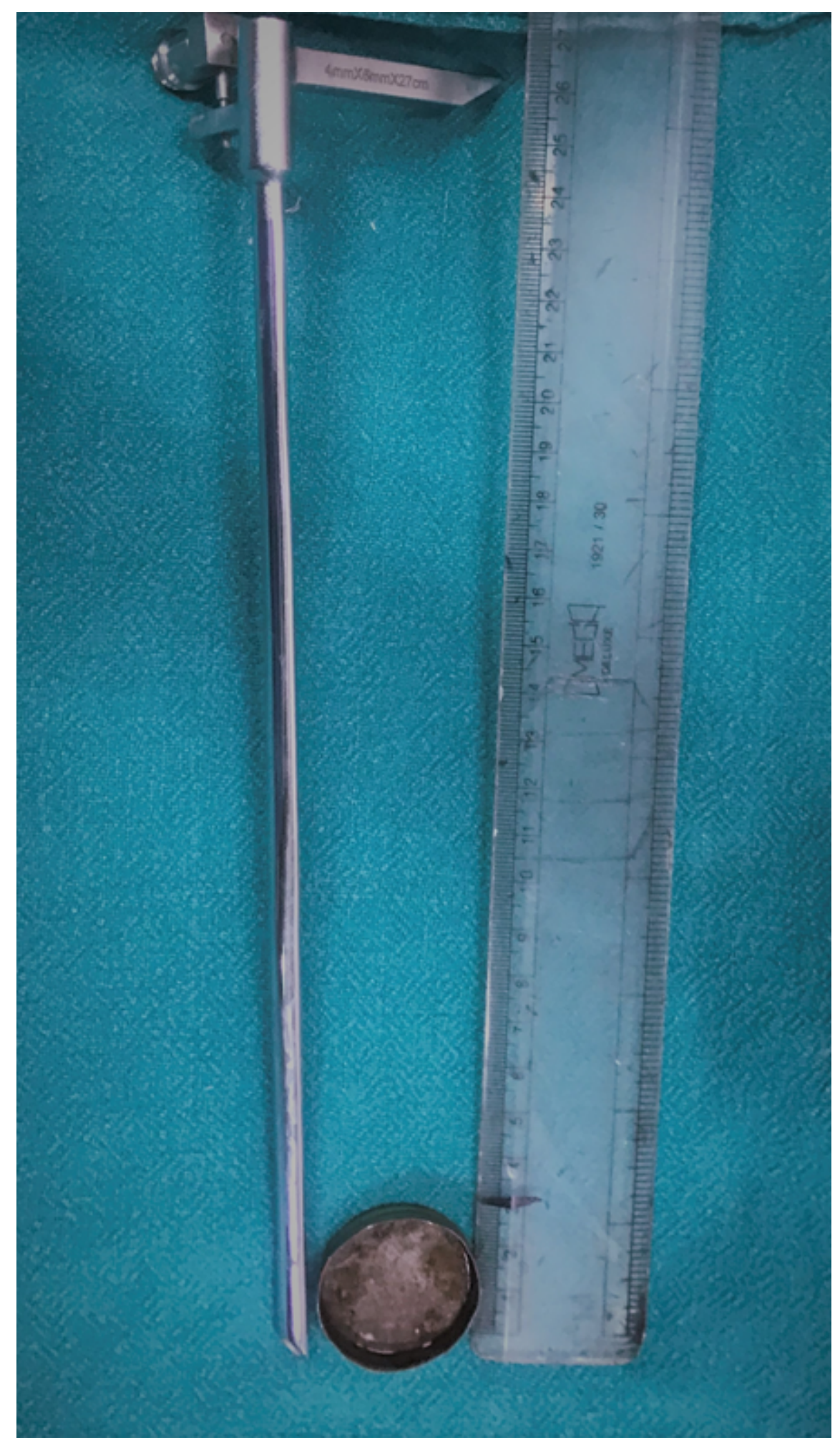

Figure $2(\mathrm{~A} \& \mathrm{~B})$; Foreign body, metallic container $(2 \mathrm{X} 2 \mathrm{~cm})$ with mirror and sharp edge opposite surface. 


\section{DISCUSSION}

Lodged foreign body in aero-digestive tract of children is one of the frequently observed conditions in pediatric emergency department. Its incidence is equal in both the genders. ${ }^{8}$ Children can swallow myriad of objects due to easy accessibility of objects like coins, toys, batteries and jewelries in households.

The vast majority of smaller smooth ingested foreign bodies will pass spontaneously via gastrointestinal tract without any damage. However, certain foreign bodies may lodge in areas of normal narrowing or curvatures of esophagus most commonly in upper esophagus i.e., cricopharynx. ${ }^{9}$

Among this FB that comes to clinical attention, 80\%-90\% pass through gastrointestinal tract (GI) without causing any harm. Another 10\%-20\% require a careful manipulation for endoscopic removal, with $<1 \%$ of foreign objects require open surgical exploration. ${ }^{5}$

Usually FB ingestion/inhalation presents with excessive drooling, poor feeding, dysphagia and vomiting and occasionally cough, stridor and wheezing. Respiratory symptoms secondary to esophageal foreign body in not uncommon presentation which is likely to be seen in a case where FB are sharp, irregular and is of large size. ${ }^{10}$

In our case, due to the large size of metallic container, it got lodged in the oropharynx as the child was not able to swallow it completely. The foreign body showed sharp edge towards the hollow surface. Notably, the sharp or jagged foreign body carries significant morbidity and mortality as they are responsible for $15 \%$ to $35 \%$ of perforations following ingestion. ${ }^{11}$

Mostly, lodged foreign body in aero-digestive tract of child is suspected when one refuses to eat or has excessive drooling and noisy breathing. However, at times there will be more straight forward diagnosis when family member reports to have witnessed the ingestion of the foreign body like in our case.

Child suspected with ingested foreign body requires minimal laboratory investigations. Antero- posterior and lateral X-ray including neck, thorax and abdomen should be obtained in patients with the complaints of FB ingestion or suspicion of ingestion. ${ }^{12}$

Sometimes in a suspicious case of FB ingestion/inhalation among the unattended child, X-ray nasopharynx is also required wen X-ray neck and chest is inconclusive. However, the ingested/inhaled FB lodging in nasopharynx as rarely been reported. ${ }^{13}$

Foreign body located in esophagus can be removed via flexible or rigid esophagoscopy or hypopharyngoscopy. Likewise other techniques like Penny-pincher technique, Foley catheter extraction, esophageal bougienage and removal with Magill forceps have been used for removal of esophageal foreign body ${ }^{14}$

In this case, a 13 month-old-girl presented with excessive drooling and noisy breathing with direct documented history of ingestion of a metallic container. Radiography revealed radiopaque vertically oriented circular foreign body in the region of oropharynx and hypopharynx. Under general anesthesia and direct laryngoscopy, safe removal of large circular metallic object was performed via Freer's elevator and Magill's forceps.

\section{Conclusion:}

Foreign body ingestion is fairly common among the pediatric age group. In the absence of straight forward diagnosis witnessed by parents of the foreign body ingestion, it should be suspected in the clinical grounds when child presents with symptoms like refusal to feed, excessive drooling and noisy breathing. Prompt diagnosis and safe intervention avoids potentially grave complication among them.

\section{Acknowledgement:}

The authors would like to acknowledge the operative room staffs of Patan Academy of Health Sciences for their help on performing the procedure. Manuscript has been prepared with full consent form the patient.

Conflict Of Interest: None 


\section{Orcid:}

Manisha Paneru: https://orcid.org/0000-0003-1612-8415

Ajit Nepal: https://orcid.org/0000-0001-6615-6516

Binam Ghimire: https://orcid.org/0000-0002-2459-8006

\section{Author Contributions:}

MP: Performed and describe the operative procedure. Conceptualization and preparation of manuscript

AN: Performed and describe the operative procedure. Critically analyzed the manuscript

BG served as anesthesiologist.

\section{REFERENCES}

1. Tasneem Z, Khan MA, Uddin N. Esophageal foreign body in neonates. J Pak Med Assoc. 2004 Mar;54(3):159-61. PMID: 15129878.

2. Singh N, Chong J, Ho J, Jayachandra S, Cope D, Azimi F, Eslick GD, Wong E. Predictive factors associated with spontaneous passage of coins: A ten-year analysis of paediatric coin ingestion in Australia. Int J Pediatr Otorhinolaryngol. 2018 Oct;113:266-271. doi: 10.1016/j.ijporl.2018.08.010. Epub 2018 Aug 10. PMID: 30173999.

3. Bekkerman M, Sachdev AH, Andrade J, Twersky Y, Iqbal S. Endoscopic Management of Foreign Bodies in the Gastrointestinal Tract: A Review of the Literature. Gastroenterol Res Pract. 2016;2016:8520767. doi: 10.1155/2016/8520767. Epub 2016 Oct 11. PMID: 27807447; PMCID: PMC5078654.

4. Litovitz TL, Klein-Schwartz W, White S, Cobaugh DJ, Youniss J, Omslaer JC, Drab A, Benson BE. 2000 Annual report of the American Association of Poison Control Centers Toxic Exposure Surveillance System. Am J Emerg Med. 2001 Sep;19(5):337-95. doi: 10.1053/ajem.2001.25272. PMID: 11555795.

5. Orsagh-Yentis D, McAdams RJ, Roberts KJ, McKenzie LB. Foreign-Body Ingestions of Young Children Treated in US Emergency Departments: 1995-2015. Pediatrics. 2019 May;143(5):e20181988. doi: 10.1542/peds.2018-1988. Epub 2019 Apr 12. PMID: 30979810.

6. Lone SA, Hameed A, Shiekh FA. Foreign body esophagus in a young infant. Clin Case Rep. 2021 Feb 27;9(4):1899-1901. doi: 10.1002/ccr3.3846. PMID: 33936611; PMCID: PMC8077303.

7. Hernot S, Kalra V, Wadhera R, Kaintura M. Sharp 3-Ended Metallic Foreign Body in an Infant Hypopharynx. Indian J Otolaryngol Head Neck Surg. 2019 Oct;71(Suppl 1):14-17. doi: 10.1007/s12070015-0908-6. Epub 2015 Sep 22. PMID: 31741920; PMCID: PMC6848338.

8. Balci AE, Eren S, Eren MN. Esophageal foreign bodies under cricopharyngeal level in children: an analysis of 1116 cases. Interact Cardiovasc Thorac Surg. 2004 Mar;3(1):14-8. doi: 10.1016/S15699293(03)00195-6. PMID: 17670166.

9. Hesham A-Kader H. Foreign body ingestion: children like to put objects in their mouth. World J Pediatr. 2010 Nov;6(4):301-10. doi: 10.1007/s12519-010-0231-y. Epub 2010 Nov 16. PMID: 21080143.

10. Pasquariello PS Jr, Kean H. Cyanosis from a foreign body in the esophagus. Respiratory difficulties three months after swallowing a coin. Clin Pediatr (Phila). 1975 Mar;14(3):223-5. doi: 10.1177/000992287501400308. PMID: 1116312.

11. Kountouras J, Chatzopoulos D, Vrettos M. Perforation of midpart of ileum caused by entrapment of a large, wide foreign body. Ann Gastroenterol 2001;14:329-332.

12. Gabriel OT, Obasa OT, Osesanmi SS. An unusual foreign body impaction in the pharynx of a child a case report and literature review. Niger Postgrad Med J. 2014 Jun;21(2):192-5. PMID: 25167598.

13. Jagdish Kumar Athmaram Gupta Sunkum. Nasopharyngeal foreign body in an young child. Indian J Otolaryngol Head Neck Surg. 2011 Jul;63(3):285-6. doi: 10.1007/s12070-011-0191-0. Epub 2011 May 8. PMID: 22754811; PMCID: PMC3138969.

14. Cetinkursun S, Sayan A, Demirbag S, Surer I, Ozdemir T, Arikan A. Safe removal of upper esophageal coins by using Magill forceps: two centers' experience. Clin Pediatr (Phila). 2006 Jan-Feb;45(1):71-3. doi: 10.1177/000992280604500111. PMID: 16429219. 